Diabetologia (1994) 37: 953-955

\title{
Why can high insulin levels indicate a risk for coronary heart disease?
}

\author{
A. Fontbonne \\ INSERM Unit 21, Villejuif, France \\ "J'aime les idées fixes, à condition d'en changer" \\ François Jacob, Nobel Prize 1965
}

Ever since it was first published that high circulating insulin levels were associated with an increased risk for coronary heart disease CHD in men [1-3], there has been controversy as to how to interpret the finding. Indeed, times are long past when the epidemiological identification of a "risk factor" automatically entailed suspicion as to its causal role towards the disease with which it was associated, but even so, the fact that any suspicion could fall on the hormone that "cures" diabetes seemed intolerable to many. RJ Jarrett was and still is among the ardent defendants of insulin. In this issue of the journal, Diabetologia publishes his updated views on the topic of insulin and atherogenesis, and thankfully opens the opportunity for debate.

\section{Insulin, epidemiology, pathophysiology and common sense}

One can say there are two (complementary) ways to ascertain the plausibility of a causal relation between a "risk factor" and a disease: finding arguments within, and finding arguments outside the epidemiological field. Epidemiology has pointed to insulin as an independent and weakly but statistically significant prospective correlate of CHD in three cohorts of middle-aged men [1-3]. The fact that the correlate (fasting insulin or stimulated insulin) could vary between $[1,3]$ and even within studies $[3,4]$ most prob-

Corresponding author: Dr. A.Fontbonne INSERM U21 16, avenue Paul Vaillant-Couturier, F-94807 Villejuif Cedex, France

Abbreviations: CHD, Coronary heart disease; NIDDM, noninsulin dependent diabetes mellitus. ably constitutes a random finding, due to variability artifacts that are known to occur in multivariate analyses, rather than an inconsistency, and in any case does not alter the interpretation given the high correlation coefficients between the two measures in a healthy population. The arguments against causality need not therefore be sought through a detailed critical review of the three above-mentioned studies. It is sufficient to remark that the result has been found so far only in healthy male middle-aged cohorts.

That the correlation between plasma insulin levels and CHD was not evidenced in the Pima Indians [5] is no wonder: this population group experience so little cardiovascular disease as to render the search for subtle risk factors extremely difficult, if not meaningless. Far more interesting is the fact that the association has never been proven in women $[2,6]$, nor seemingly in elderly men [7]. Inconsistent results in cohorts of diabetic or glucose-intolerant subjects also plead in favour of an absence of a causal relationship between hyperinsulinaemia and CHD [8]. If an excess of circulating insulin was actually toxic for the arteries, it would be difficult (though not impossible - specific protective factors in the female? Survival biases in the elderly?) to explain why this toxicity be expressed only in middle-aged non-diabetic men. Hence, epidemiology itself provides arguments against a causal relationship between insulin and cardiovascular disease.

From outside the field of epidemiology come arguments of another kind. Few biological studies have demonstrated a direct deleterious effect of insulin or insulin-like factors on the arterial wall - essentially a proliferation of muscle cells in the media, generally observed with insulin perfusions far above the physiological range [9]. On the other hand several clinical studies have shown, and this is acknowledged by Jarrett himself as "ample evidence", that hyperinsulinaemia is generally associated with a cluster of 
"well-documented risk factors for CHD", among which are elevated blood pressure, low HDL-cholesterol levels and high triglycerides. This raises the possibility that hyperinsulinaemia appears to be linked to an increased cardiovascular risk because it indicates the presence of this cluster of plausibly atherogenic abnormalities. The question now is: why only in male middle-aged non-diabetic Caucasians?

Jarrett proposes a somewhat surprising answer to this question, by assigning to hyperinsulinaemia a protective role against the deleterious effects of the "well-documented risk factors" to which it is associated. It is always difficult to derive pathophysiological explanations directly from epidemiological correlations, as we have just seen, but this hypothesis certainly challenges one's common sense. If it were to be accepted, an alternative explanation would be needed to account for the negative correlation of HDL-cholesterol (a protective factor which increases - epidemiologically speaking - with total cholesterol) with cardiovascular events.

More reasonably, one could suggest that high levels of circulating insulin may not always be the best indicator of the above-mentioned cluster of risk factors. For instance, it is well known that hyperinsulinaemia and obesity go hand in hand, which would mean rather "android" (centrally-distributed) obesity in men, and "gynoid" (peripherally-distributed) obesity in women. Jarrett is right to point out that an excess of visceral fat, typical of android obesity, is indeed associated with a greater risk of cardiovascular events, both in men and women [10], and it is actually together with android obesity that the cluster of cardiovascular risk factors can most easily be found [11]. Since in epidemiological cohorts hyperinsulinaemic women are generally gynoid obese and therefore not excessively at risk for cardiovascular disease, plasma insulin levels cannot be expected to relate to CHD.

In NIDDM subjects - who are typically android obese -, hyperinsulinaemia is generally present, together with the accompanying cluster of risk factors. However, as the duration of the glycaemic disorder increases, the levels of plasma insulin decrease [12], and this hardly qualifies them, from a statistical point of view, for a positive correlation with cardiovascular events. Indeed, the best indicator of the cluster of CHD risk factors in this case appears to be a more markedly android distribution of fat and a higher level of plasma triglycerides, which are the strongest predictors of CHD mortality in diabetic and glucose-intolerant subjects [13].

All this may readily account for what Jarrett calls "inconsistencies" in the relationship between insulin and cardiovascular disease. Plasma insulin is not the most ubiquitous indicator of the existence of a potentially atherogenic syndrome. As its measurement is relatively time-consuming, expensive and poorly specific, a suggestion could be to replace it with a much cheaper and easier one: the measurement of the waist and the hip circumferences, the ratio of which gives a pretty good idea of the distribution of body fat.

\section{Insulin, not insulin, and the "small baby" hypothesis}

In the last paragraph of his article, Jarrett briefly mentions two recent British contributions more or less related to the topic of insulin and cardiovascular disease. The first one concerns the imprecisions of the radioimmunological assay of insulin, the one commonly used in epidemiological studies, which does not distinguish between "true" insulin and its much less active precursors [14]. This may provide an explanation to the fact that "hyperinsulinaemic" men appear insulin resistant (they may have a lesser proportion of active insulin compared to "normoinsulinaemic" men). However, it is to be remembered that in diabetic or glucose-intolerant subjects, supposedly the most deficient in active insulin despite usually "hyperinsulinaemic", plasma "total insulin-like molecules" are seldom if ever associated with cardiovascular complications, as we and Jarrett himself, in the first part of his paper, have mentioned.

The hypothesis of Hales and Barker [15] of a fetal programming of future disease in adulthood is also mentioned by Jarrett, though it seems peripheral to the present issue (unless Jarrett would now accuse insulin or its precursors to be risk determinants of cardiovascular complications?). It is also extremely questionable, since Hales and Barker's observations were made on groups of elderly subjects, whose childhood took place immediately before or during the Second World War. Could it simply be that "small babies" with little or no capacity for storing fat did not survive the harsh circumstances of their childhood? Hence "small babies" who survived (studied much later by Barker) are more prone to obesity, NIDDM and cardiovascular disease later in life? And that actually a cluster of risk factors would protect "small babies"?

\section{Conclusion}

Finally, Jarrett's article, though it may appear to verge on the polemic, proves that a kind of consensus has emerged between researchers in the field. Epidemiology has led us to identify (some may say: to rediscover, but this is another debate) an "at-risk" situation, i.e. the cluster of potentially atherogenic abnormalities generally associated with android obesity. Causality in the relationship between this cluster and cardiovascular events is plausible, since for at least some of its elements - and the list is not final - there exist physiological observations which constitute stronger arguments for a deleterious effect on arteries than is the case for insulin [16]. Having put insulin on trial has 
served a double aim: it has found no evidence of guilt, and it has revealed that high levels of the hormone can nevertheless indicate a situation of greater cardiovascular risk, usually associated with an android distribution of body fat.

\section{References}

1. Pyörälä K (1979) Relationship of glucose tolerance and plasma insulin to the incidence of coronary heart disease: results from two population studies in Finland. Diabetes Care 2: 131-141

2. Welborn TA, Wearne K (1979) Coronary heart disease incidence and cardiovascular mortality in Busselton with reference to glucose and insulin concentrations. Diabetes Care 2: 154-160

3. Ducimetière P, Eschwège E, Papoz L, Richard JL, Claude JR, Rosselin G (1980) Relationship of plasma insulin levels to the incidence of myocardial infarction and coronary heart disease mortality in a middle-aged population. Diabetologia 19: $205-210$

4. Fontbonne A, Charles MA, Thibult N et al. (1991) Hyperinsulinaemia as a predictor of coronary heart disease mortality in a healthy population: The Paris Prospective Study, 15-year follow-up. Diabetologia 34: 356-361

5. Liu QZ, Knowler WC, Nelson RG et al. (1992) Insulin treatment, endogenous insulin concentration and ECG abnormalities in diabetic Pima Indians: cross-sectional and prospective analyses. Diabetes 41: 1141-1150

6. Fontbonne A (1991) Insulin, a sex hormone for cardiovascular risk? Circulation 84: 1442-1444
7. Welin L, Eriksson H, Larsson B, Ohlson LO, Svärdsudd K, Tibblin G (1992) Hyperinsulinaemia is not a major coronary risk factor in elderly men: the study of men born in 1913. Diabetologia 35: 766-770

8. Fontbonne A (1992) Relationship between diabetic dyslipoproteinaemia and coronary heart disease risk in subjects with non-insulin-dependent diabetes mellitus. Diabetes Metab Rev 7:179-189

9. Stout RW (1990) Insulin and atheroma. 20-yr perspective. Diabetes Care 13: 631-654

10. Larsson B, Bengtsson C, Björntorp P et al. (1992) Is abdominal body fat distribution a major explanation for the sex difference in the incidence of myocardial infarction? The study of men born in 1913 and the study of women, Göteborg, Sweden. Am J Epidemiol 135: 266-273

11. Kissebah AH (1991) Insulin resistance in visceral obesity. Int J Obesity 15: 109-115

12. DeFronzo RA (1988) The triumvirate: $\beta$-cell, muscle, liver. A collusion responsible for NIDDM. Diabetes 6: 667-687

13. Fontbonne A, Thibult N, Eschwège E, Ducimetière $P(1992)$ Body fat distribution and coronary heart disease mortality in subjects with impaired glucose tolerance or diabetes mellitus: The Paris Prospective Study, 15-year follow-up. Diabetologia 35: 464-468

14. Temple RC, Carrington CA, Luzio SD et al. (1989) Insulin deficiency in non-insulin-dependent diabetes. Lancet I: 293-295

15. Hales CN, Barker DJP (1992) Type 2 (non-insulin-dependent) diabetes mellitus: The thrifty genotype hypothesis. Diabetologia 35: 595-601

16. Austin MA (1991) Plasma triglyceride and coronary heart disease. Arterioscler Thromb 11:2-14 